\title{
Efeito da secagem em leito nas características físico-químicas e microbiológicas de lodo de reator anaeróbio de fluxo ascendente usado no tratamento de esgoto sanitário
}

\author{
Effect of bed drying on the physico-chemical and microbiological \\ characteristics of sludge from upflow anaerobic \\ blanket reactor used in sewage treatment \\ Dalila Souza Santos', Elisa Teshima², Sandra Maria Furiam Dias ${ }^{3}$, \\ Roque Angelico Araújo ${ }^{4}$, Cristina Maria Rodrigues da Silva ${ }^{5}$
}

口-

\section{RESUMO}

Os processos de tratamento de lodo de esgoto visam reduzir o teor de material orgânico biodegradável, a concentração de organismos patogênicos e a umidade a fim de se obter um material que não constitui risco à saúde ambiental e que possa ser utilizado para fins agrícolas. Nesse sentido, este trabalho teve como objetivo avaliar o efeito da secagem em leito nas características microbiológicas e físico-químicas de lodo de esgoto doméstico de reator anaeróbico de fluxo ascendente (UASB). As amostras de lodo foram retiradas a 4,8 m de profundidade (lodo A) e a 3,1 m (lodo B) do reator UASB, totalizando 3 coletas, com intervalo de 1 mês. As amostras coletadas foram submetidas ao processo de secagem em células de leitos de secagem (1,00 $\times 2,00 \times 0,50 \mathrm{~m}$ ). De cada célula foram coletadas 6 amostras nos tempos 0, 7, 15, 30, 60 e 90 dias. Foram determinados os parâmetros: sólidos totais, sólidos voláteis, temperatura, $\mathrm{pH}$, umidade, carbono orgânico total, N, P, K, Mg, $\mathrm{Na}, \mathrm{Ca}, \mathrm{Mn}, \mathrm{Cd}, \mathrm{Co}, \mathrm{Cu}, \mathrm{Ni}, \mathrm{Pb}, \mathrm{Zn}$, lipídios, coliformes totais e termotolerantes, Salmonella e ovos viáveis de helmintos. Não houve diferença físico-química, microbiológica e parasitológica entre o lodo A e o B após o período de secagem. As concentrações finais dos nutrientes, metais pesados e a relação $\mathrm{C} / \mathrm{N}$ conferem aos lodos um potencial agronômico. Entretanto, a baixa inativação dos microrganismos permite concluir que o processo de secagem em leito é ineficiente para redução de patógenos. Os biossólidos gerados em ambos os tratamentos são classificados como tipo B (CONAMA 375/06).

Palavras-chave: lodo de esgoto; reator UASB; microrganismos patogênicos; leito de secagem, uso agrícola.

\begin{abstract}
The sludge treatment process intended to reduce the content of biodegradable organic material, the concentration of pathogens and moisture in order to obtain a solid and stable material, which is not hazardous to the environment health and useful for agricultural purposes. This study aims to evaluate the effects of bed drying on physicochemical and microbiological characteristics of domestic sewage sludge samples taken from an upflow anaerobic sludge blanket (UASB) reactor. Sludge samples were collected at $4.8 \mathrm{~m}$ from the bottom (sludge A) and $3.1 \mathrm{~m}$ (sludge B) of an UASB reactor, totaling 3 collections, with an interval of 1 month. Each collected sample was subjected to the sludge drying process in cells of drying beds $(1.00 \times 2.00$ x 0.50 m). In each cell, 6 samples were collected at 0, 7, 15, 30, 60 and 90 days. The following parameters were evaluated: total solids, volatile solids, temperature, $\mathrm{pH}$, moisture content, total organic carbon, N, P, K, Mg, Na, Ca, $\mathrm{Mn}, \mathrm{Cd}, \mathrm{Co}, \mathrm{Cu}, \mathrm{Ni}, \mathrm{Pb}, \mathrm{Zn}$, lipids, total and fecal coliforms, Salmonella and viable helminth eggs. No physical-chemical, microbiological and parasitological differences between sludge $A$ and sludge $B$ were detected after the period of bed drying. The final concentrations of nutrients and heavy metals as well as the $\mathrm{C} / \mathrm{N}$ ratio were considered adequate for agricultural purposes. However, the low inactivation of microorganisms indicated the inefficiency of drying beds regarding the removal of pathogen microorganisms. The generated biosolids in both treatments are classified as type B (CONAMA 375/06).
\end{abstract}

Keywords: sewage sludge; UASB; pathogenic microorganisms; bed drying; agricultural use.

\footnotetext{
'Doutoranda em Biotecnologia pela Universidade Estadual de Feira de Santana (UEFS) - Feira de Santana (BA), Brasil.

²Doutora em Ciência e Tecnologia de Alimentos pela Universidade Federal de Viçosa (UFV). Professora Adjunta do Departamento de Tecnologia da UEFS - Feira de Santana (BA), Brasil. ${ }^{3}$ Doutora em Saúde Pública pela Universidade de São Paulo (USP). Professora Permanente do Curso de Mestrado em Engenharia Civil e Ambiental da UEFS - Feira de Santana (BA), Brasil. ${ }^{4}$ Doutor em Saúde Pública pela Universidade de São Paulo (USP). Professor Adjunto do Departamento de Tecnologia da UEFS - Feira de Santana (BA), Brasil.

${ }^{5}$ Doutora em Ciência de Alimentos pela Universidade Estadual de Campinas (UNICAMP). Professora Adjunta do Departamento de Tecnologia da UEFS - Feira de Santana (BA), Brasil. Endereço para correspondência: Dalila de Souza Santos - Laboratório de Pesquisa em Microbiologia (LAPEM), Departamento de Ciências Biológicas (DCBio), Universidade Estadual de Feira de Santana. Avenida Transnordestina, s/n - Novo Horizonte - 44036-900 - Feira de Santana (BA), Brasil - E-mail: dalilassouza@gmail.com Recebido: 27/08/12 - Aceito: 07/07/16 - Reg. ABES: 100531
} 


\section{INTRODUÇÃO}

A necessidade de se atender às exigências ambientais, quanto à destinação adequada do lodo de esgoto, tem sido uma das maiores dificuldades enfrentadas no setor de saneamento nos dias de hoje. Os processos de tratamento de lodo visam reduzir o teor de material orgânico biodegradável, a concentração de organismos patogênicos e o teor de água, a fim de se obter um material sólido e estável, que não constitua risco à saúde e que possa ser manipulado e transportado com facilidade e baixo custo. Existem várias alternativas para o tratamento e a destinação final do lodo. A mais comum envolve o tratamento biológico por meio da digestão aeróbica ou anaeróbica, que pode ser seguida pela destinação final em aterros sanitários, landfarming, lagoas de armazenagem, incineração ou reciclagem agrícola (WAGNER et al., 2009). Essa última é a de maior interesse atualmente, devido à composição rica em macro e micronutrientes que o lodo possui.

O lodo gerado em um reator anaeróbico de fluxo ascendente (UASB) normalmente é estável o suficiente para permitir a separação sólido-líquido sem tratamento preliminar, pois, ao contrário do lodo de sistemas de lodos ativados, não é necessário o tratamento. Uma vez retirado do UASB, o lodo passa para a etapa de desaguamento, a qual pode ser realizada por métodos mecânicos ou por secagem natural. Dentre os métodos de secagem naturais mais comuns estão os leitos de secagem, devido ao custo de implantação reduzido, bem como à simplicidade da operação e manutenção de seu processo.

Para o reaproveitamento do lodo gerado em estações de tratamento de esgoto (ETEs), é necessário seguir um programa de planejamento e monitoramento adequado, no qual devem ser analisadas as adequações necessárias para as ETEs e o monitoramento ambiental, as alternativas de higienização, a aptidão das áreas de aplicação e operação da distribuição, a estimativa da produção, bem como a avaliação da qualidade.

A fim de evitar o uso indevido do lodo contaminado com organismos patogênicos e metais pesados, de forma que se assegure a salubridade ambiental e a segurança pública, vários países formularam diretrizes que orientam o uso adequado desse biossólido na agricultura, a exemplo do Brasil, por meio da Resolução CONAMA n 375/06 (BRASIL, 2006), dos Estados Unidos, com os padrões estabelecidos pela Agência de Proteção Ambiental (USEPA, 2003), e dos países da União Europeia, com as diretrizes presentes no 86/278/EEC (FYTILI \& ZABANIOTOU, 2008).

Dado o exposto, este trabalho objetivou avaliar o potencial agronômico e o efeito da secagem em leito nas características microbiológicas e físico-químicas de amostras de lodo obtidas de um UASB que trata esgoto doméstico.

\section{METODOLOGIA}

O lodo utilizado neste estudo foi retirado em dois pontos distintos do UASB da ETE em Feira de Santana, o qual possui $12 \mathrm{~m}$ de largura,
$12 \mathrm{~m}$ de comprimento e $5 \mathrm{~m}$ de altura. O primeiro ponto de coleta foi do leito de lodo, a 4,8 $\mathrm{m}$ de profundidade (lodo A), e o segundo foi da região da manta de lodo, a 3,1 m de profundidade (lodo B). A distância entre a coleta de um ponto para o outro no reator foi de $5,2 \mathrm{~m}$. O lodo foi retirado nos dois pontos por uma bomba de sucção e transportado em caminhões limpa-fossa distintos.

Foram realizadas três descargas de cada ponto do reator (A e B), com intervalo de um mês entre elas, sendo que a primeira ocorreu após seis meses de funcionamento do reator, que iniciou a operação sem inóculo. Cada descarga de lodo coletado foi encaminhada para uma célula de leito de secagem em escala-piloto, totalizando seis leitos, sendo três para cada ponto (Figura 1). Essas células apresentavam $1,00 \times 2,00 \times 0,50 \mathrm{~m}$, com área superficial de $2 \mathrm{~m}^{2}$, fundo com declividade em direção à tubulação de coleta do líquido percolado e camadas drenantes constituídas por materiais de diferentes granulometrias, de acordo com a NBR 12.209 (ABNT, 1992).

Foi coletado aproximadamente $1,2 \mathrm{~m}^{3}$ de lodo em cada ponto do UASB, sendo que $1 \mathrm{~m}^{3}$ foi despejado na célula de leito. Os leitos permaneceram sem cobertura durante todo o experimento, a fim de simular as mesmas condições de secagem da ETE. O período de monitoramento do lodo ocorreu entre os meses de agosto de 2010 e janeiro de 2011, e a partir de cada célula de leito foram realizadas 6 coletas ao longo de 90 dias (nos tempos 0, 7, 15, 30, 60 e 90 dias).

\section{Parâmetros físico-químicos}

A análise físico-química do lodo de esgoto consistiu na determinação dos parâmetros que indicam estabilização do lodo e caracterização do seu potencial agronômico, com exceção do nitrogênio amoniacal, do nitrito e do nitrato. Nesse sentido, foram realizados ensaios de sólidos totais (ST), sólidos voláteis (SV), umidade, carbono orgânico total (COT), nitrogênio total, temperatura e $\mathrm{pH}$ nos tempos 0 , 7, 15, 30, 60 e 90 dias; determinação dos nutrientes (P, K, Mg, Na, $\mathrm{Ca}, \mathrm{Mn}$ ) e dos metais pesados ( $\mathrm{Cd}, \mathrm{Co}, \mathrm{Cu}, \mathrm{Ni}, \mathrm{Pb}, \mathrm{Zn}$ ) aos 90 dias; e determinação dos lipídios nos tempos 0 e 90 dias. Essas análises foram realizadas em triplicata e a determinação da concentração foi dada em peso seco para todos os parâmetros. Para a determinação do $\mathrm{pH}$ foi utilizado o método eletrométrico, e para os ST e SV, o método gravimétrico (APHA/AWWA/WEF, 1998). A umidade foi calculada pela equação (\%umidade $=100-\% S T)$ (ABNT, 1989). A partir dos valores de SV, utilizou-se o fator de correção $(f=1,8)$ para obtenção dos dados de COT. A relação $\mathrm{C} / \mathrm{N}$ foi obtida a partir do valor de COT e de nitrogênio total. O nitrogênio total foi determinado segundo o método Kjedahl, e o fósforo segundo o método do ácido ascórbico (APHA/AWWA/WEF, 1998), já para os demais nutrientes e metais pesados foi utilizada a técnica de espectrofotometria de absorção atômica (EPA 7000B e 3050B/2007), e para o lipídio total foi utilizado o método de Bligh \& Dyer (CECCHI, 1999). 


\section{Parâmetros microbiológicos}

As análises microbiológicas realizadas incluíram a determinação de coliformes totais (CTO) e termotolerantes (CTE) e presença ou ausência de Salmonella spp. nos tempos 0, 7, 15, 30, 60 e 90 dias. A determinação de CTO e CTE foi realizada por meio do método do número mais provável (NMP) por tubos múltiplos em caldo lauril sulfato triptose, verde brilhante bile lactose $2 \%$ (VBBL) e E. coli (EC) (APHA/ AWWA/WEF, 1998). Pelo método de plaqueamento superficial de amostras diluídas (1:10), foi observada a presença de Salmonella spp em ágar cromogênico (HiCrome). A determinação da quantidade de ovos viáveis de helmintos foi realizada pelo método de centrifugação de Silva et al. (2007).

\section{Análise estatística dos dados}

Todos os dados foram submetidos à análise de variância (ANOVA) a 5\% de probabilidade para comparação entre os dois tratamentos estudados. Os dados obtidos em função do tempo de secagem foram avaliados por ANOVA, e quando apresentaram efeitos significativos foram submetidos ao teste de comparação de médias de $t$ de Student, para amostras com duas varáveis, ou ao teste de Scott-Knott, para comparação múltipla de variáveis, dentro do mesmo tratamento. Os testes foram realizados no programa SISVAR versão 4.6.

\section{RESULTADOS E DISCUSSÃO}

No período experimental, as temperaturas médias dos lodos $\mathrm{A}$ $(4,8 \mathrm{~m})$ e $\mathrm{B}(3,1 \mathrm{~m})$ (Tabela 1$)$ variaram de 22 a $30^{\circ} \mathrm{C}$. A temperatura inicial ( $1^{\circ} \mathrm{dia}$ ) diferiu das demais devido à leitura ter sido realizada por volta do meio-dia, enquanto os outros registros foram feitos às sete horas da manhã.

\section{Avaliação físico-química do lodo}

A Tabela 1 mostra a evolução das porcentagens de umidade, SV e ST, a relação SV/ST e o pH ao longo do processo de secagem. Considerando os valores iniciais dos lodos A (4,8 m) e B (3,1 m), observa-se que eles apresentam grandes diferenças. Isso se deve ao fato de terem sido retirados de diferentes regiões do reator. O lodo A, coletado da região de leito de lodo, está constantemente recebendo esgoto fresco, carregado de material orgânico, por isso apresenta valores percentuais de SV altos.

Como no reator o esgoto é tratado de forma ascendente, a região da manta de lodo é uma área de turbulência e muita heterogeneidade de materiais. Nesse sentido, o lodo, ao passar pela manta, carreia uma parte dos sólidos presentes, que pela ação da gravidade decanta e se deposita no leito de esgoto. Isso explica o fato de o lodo A (leito) possuir maior concentração de sólidos do que o lodo B (manta).

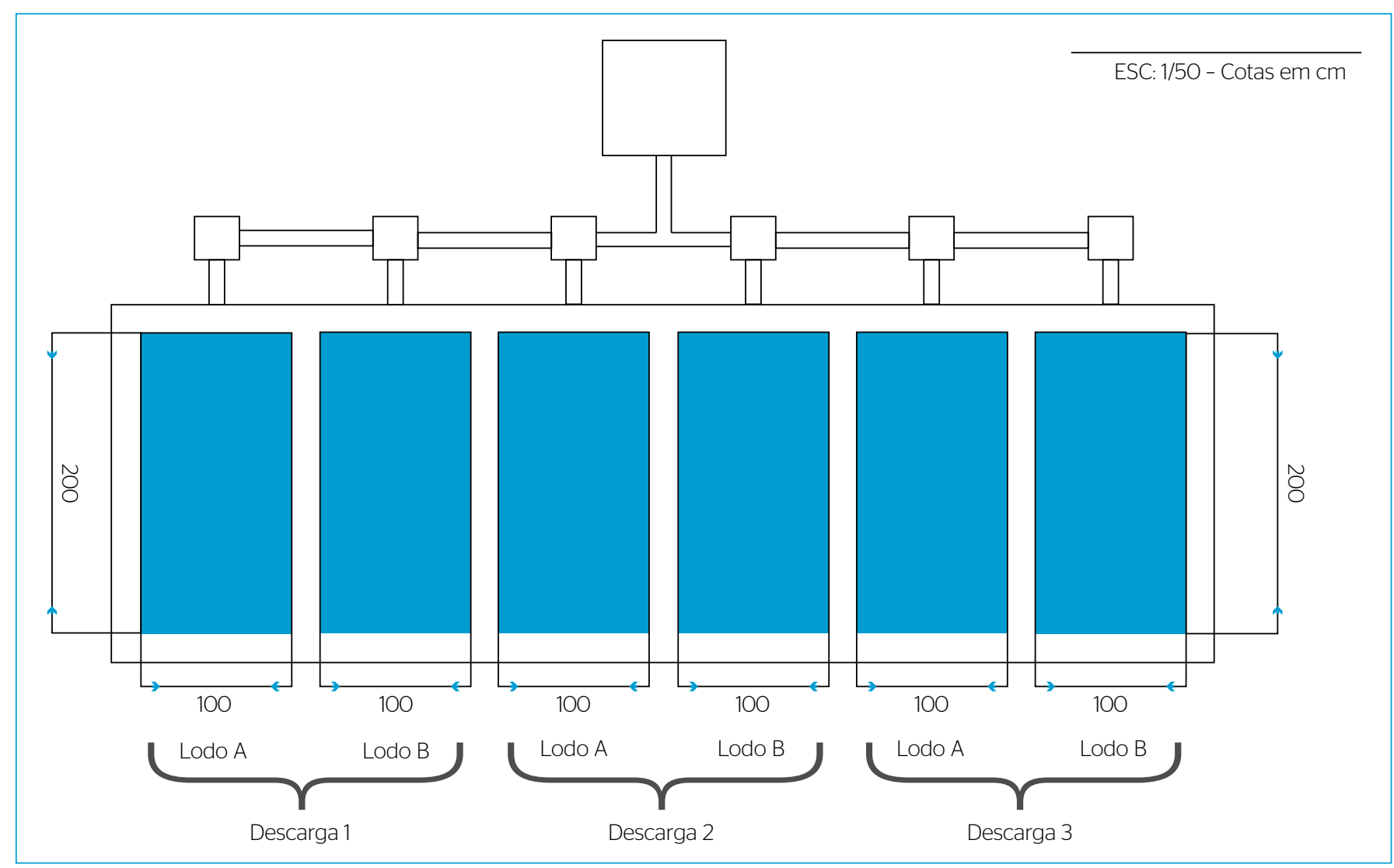

Figura 1 - Disposição das descargas e dos leitos de secagem no sistema experimental. 
Em relação aos processos de bioconversão do lodo dentro do reator, sabe-se que é na região do lançamento do esgoto fresco (local de entrada desse material no reator) que se inicia esse processo, pela atividade de bactérias anaeróbias presentes, ocorrendo hidrólise, acidogênese e acetogênese, resultando na liberação de ácidos graxos. Isso implica em valores mais baixos de $\mathrm{pH}$ no lodo presente nessa região. Já na manta de lodo, o processo de digestão já se encontra na fase metanogênica, na qual os compostos formados são transformados em metano, fazendo com que o $\mathrm{pH}$ dessa região se eleve.

Em geral, verificou-se que apesar de ambos os tratamentos apresentarem mais de $90 \%$ de umidade no início do processo, o lodo B alcança um teor de sólido satisfatório para sua remoção do leito, aproximadamente no $30^{\circ}$ dia de exposição, enquanto para o lodo A esse teor é observado no $60^{\circ}$ dia (Tabela 1 ). Isso implica afirmar que o lodo B possui melhores condições de desaguamento do que o lodo A, necessitando, assim, de menor ciclo de secagem em leito, o que ocorre devido à diferença inicial da concentração de ST entre esses dois lodos (5,39 e 1,46\%, para os lodos A e B, respectivamente). Entretanto, considerando o parâmetro de dimensionamento dos leitos de secagem da ETE, o melhor lodo a ser descartado do reator seria o lodo A, pois, devido ao seu maior percentual inicial de sólidos, demandaria um menor volume de lodo excedente a ser descartado do reator e, consequentemente, requereria menor área para o leito de secagem.

Na relação SV/ST, obtida aos 90 dias, observa-se que os lodos A e B alcançaram estabilidade (SV/ST $<0,70$, segundo a Resolução CONAMA no 375/06). Os dados obtidos indicam que houve efeito $(\alpha=0,05)$ do tempo de secagem em leito sobre os parâmetros citados: a partir do $7^{\circ}$ dia para o lodo A e a partir do $30^{\circ}$ dia para o lodo B.
Os ST dos lodos A e B no $30^{\circ}$ dia se assemelham aos resultados de Salihoglu, Pinarli e Salihoglu (2007), que submeteram o lodo de esgoto ao desaguamento mecânico e, em seguida, o dispuseram à secagem em leitos cobertos com ventilação forçada, alcançando percentual de ST de $35 \%$ em 15 dias no verão e 30 dias no inverno. O SV inicial nesse estudo foi de $60,4 \%$, semelhante ao SV inicial dos lodos A e B.

Em relação ao $\mathrm{pH}$, verifica-se que o lodo $\mathrm{A}$ apresentou maior variação $(5,9-7,8)$ do que o lodo $B(7,3-6,0)$ e uma diminuição $(\mathrm{p}<0,05)$ foi observada a partir do $60^{\circ}$ dia de secagem.

A redução do $\mathrm{pH}$ ao longo do tempo de retenção no leito de secagem é consequência da atividade microbiana, na qual, durante o processo de decomposição, ocorre a quebra de material orgânico complexo em ácidos orgânicos intermediários, o que resulta na diminuição desse pH (BERTOLDI; VALLINI; PERA, 1983).

Na Tabela 2 estão apresentas as porcentagens de COT, NT e lipídios, bem como a relação $\mathrm{C} / \mathrm{N}$ nos lodos estudados. Quanto à concentração de lipídios totais, a ANOVA realizada demonstrou que os lodos A e B são estatisticamente iguais. Quando analisados os tratamentos individualmente, foi observada diferença $(\alpha=0,10)$ entre o início e o final do processo de secagem para ambos os tratamentos, com redução do teor de gordura de 64 e 52\%, para os lodos A e B, respectivamente.

A presença de ácidos graxos no lodo é preocupante, pois a exposição dos microrganismos ao lipídio afeta a distribuição da biomassa, conferindo-lhes, muitas vezes, resistência ao calor. No estudo realizado por Alves et al. (2001), no qual foi avaliado o desenvolvimento da biomassa em reatores anaeróbios sem lipídio e com lipídio em diferentes concentrações, observou-se que o biofilme formado com a presença de lipídio era mais resistente do que o biofilme formado sem a presença do lipídio.

Tabela 1 - Valores médios e desvios padrão da umidade, sólidos totais, sólidos voláteis, relação sólidos totais/sólidos voláteis, pH e temperatura dos tratamentos durante o período de secagem em leito.

\begin{tabular}{|c|c|c|c|c|c|c|c|}
\hline Ponto de coleta & Tempo (dias) & Umidade (\%) & Sólidos totais (\%) & Sólidos voláteis (\%) & $\begin{array}{l}\text { Relação sólidos } \\
\text { totais/sólidos voláteis }\end{array}$ & $\mathrm{pH}$ & $\begin{array}{c}\text { Temperatura } \\
\left({ }^{\circ} \mathrm{C}\right)\end{array}$ \\
\hline \multirow{6}{*}{$\begin{array}{l}\text { A } \\
(4,8 \mathrm{~m})\end{array}$} & 0 & $94,61 \pm 1,53 a$ & $5,39 \pm 1,53 d$ & $56,00 \pm 3,37 a$ & & $6,80 \pm 0,20 b$ & $30,33 \pm 1,53$ \\
\hline & 7 & $81,01 \pm 1,52 b$ & $18,99 \pm 1,52 c$ & $57,02 \pm 4,23 a$ & & 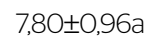 & $24,33 \pm 2,31$ \\
\hline & 15 & $78,55 \pm 2,73 b$ & $21,45 \pm 2,73 c$ & $50,23 \pm 2,01 b$ & & $7,40 \pm 0,35 a$ & $22,00 \pm 1,00$ \\
\hline & 30 & $75,78 \pm 2,96 b$ & $24,22 \pm 2,96 c$ & $45,08 \pm 3,63 c$ & & 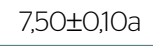 & $23,67 \pm 3,05$ \\
\hline & 60 & $60,30 \pm 9,43 c$ & $39,87 \pm 9,72 b$ & $39,41 \pm 2,27 d$ & & $6,30 \pm 0,92 b$ & $24,00 \pm 1,00$ \\
\hline & 90 & $40,58 \pm 5,93 d$ & $59,42 \pm 5,93 a$ & $34,11 \pm 1,66 d$ & $0,57 \pm 0,08$ & $5,90 \pm 0,21 b$ & $24,00 \pm 1,00$ \\
\hline \multirow{6}{*}{$\begin{array}{l}B \\
(3,1 \mathrm{~m})\end{array}$} & 0 & $98,54 \pm 1,03 a$ & $1,46 \pm 1,03 b$ & $64,38 \pm 7,15 a$ & & $7,30 \pm 0,25 a$ & $30,00 \pm 1,00$ \\
\hline & 7 & $88,60 \pm 6,60 a$ & $11,40 \pm 6,60 \mathrm{~b}$ & 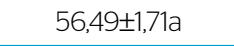 & & $7,20 \pm 0,10 a$ & $23,67 \pm 0,58$ \\
\hline & 15 & 81,18土7,53a & $18,82 \pm 7,53 b$ & $55,93 \pm 5,12 a$ & & $7,30 \pm 0,46 a$ & $22,00 \pm 1,00$ \\
\hline & 30 & $69,98 \pm 14,27 a$ & $30,02 \pm 14,27 b$ & $46,33 \pm 8,21 b$ & & $6,70 \pm 0,20 a$ & $23,00 \pm 3,00$ \\
\hline & 60 & $36,16 \pm 14,14 b$ & $63,84 \pm 14,14 a$ & $39,54 \pm 1,72 b$ & & 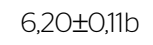 & $24,00 \pm 1,00$ \\
\hline & 90 & $22,94 \pm 16,04 b$ & $77,06 \pm 16,04 a$ & $35,99 \pm 1,92 b$ & $0,48 \pm 0,10$ & $6,00 \pm 0,56 b$ & $23,33 \pm 0,58$ \\
\hline
\end{tabular}

Médias ( $n=3$ ) seguidas de mesma letra na coluna de um mesmo ponto de coleta não diferem entre si, pelo teste de Scott-Knott ( $\alpha=0,05)$. 
As concentrações de COT (Tabela 2) foram reduzindo gradativamente ao longo dos 90 dias $(\mathrm{p} \leq 0,05)$. Para o lodo $\mathrm{A}$, os valores diminuíram a partir do $15^{\circ}$ até o $60^{\circ}$ dia, enquanto no lodo $B$ os valores apresentaram redução a partir do $30^{\circ}$ dia $(\mathrm{p} \leq 0,05)$, não variando até o final do processo de secagem. A redução de COT pode ser justificada pelos processos de decomposição aeróbia e anaeróbia da matéria orgânica, nos quais parte do carbono é liberada na forma de gás carbônico e metano.

Os valores de COT, para ambos os tratamentos, são semelhantes à média de 38,3\% encontrada por Dacera \& Babel (2008), que caracterizaram o lodo proveniente de uma ETE na Tailândia, resultante de digestão anaeróbia e posterior desaguamento em filtro de pressão. Carbonell et al. (2009) encontraram valor de 25,24\% em amostras de lodo retirado de ETE no sul da Espanha, submetido à estabilização anaeróbia termofílica.

Os percentuais de $\mathrm{N}$ (Tabela 2), para ambos os tratamentos, não diferiram estatisticamente entre os tempos analisados. Não houve perda nem ganho desse componente, permanecendo os valores praticamente invariáveis do início ao final do período de análise.

A redução de $\mathrm{C} / \mathrm{N}$ (Tabela 2) passa a ser significativa apenas a partir do $15^{\circ}$ dia, para ambos os tratamentos, devido à redução dos níveis de COT. Os valores finais de 5,42 e 5,99 para os lodos A e B, respectivamente, estão de acordo com a média encontrada no manual do Programa de Pesquisa em Saneamento Básico (PROSAB, 1999), variando entre 5 e 11 .
Segundo Bertoldi, Vallini e Pera (1983), baixas relações de C/N provocarão um retardamento no processo de decomposição, bem como aumento da perda de nitrogênio. Se as taxas iniciais são altas, os microrganismos irão oxidar o excesso de carbono, até que a relação $\mathrm{C} / \mathrm{N}$ chegue a um valor mais conveniente para seu metabolismo. Em lodos ativados essa faixa está entre 6 e 8, enquanto em lodos sem tratamento (crus) está entre 7 e 12. Os valores de C/N estão de acordo com Agustini \& Onofre (2007), que encontraram o valor de 5,00 em lodo seco, e com Guedes et al. (2006), que encontraram o valor de 9,23 em ETE no Brasil.

Os resultados das análises de macronutrientes $(\mathrm{P}, \mathrm{K}, \mathrm{Ca}$ e $\mathrm{Mg})$ e micronutrientes ( $\mathrm{Mn}$ e $\mathrm{Na}$ ) estão representados na Tabela 3 (com exceção de nitrogênio, Tabela 2). Pelo teste de Student-Newman-Keuls (SNK) $(\alpha=0,05)$, os lodos A e B são estatisticamente semelhantes para esses parâmetros.

A diferença nas oscilações dos teores de nutrientes entre os lodos A e $B$ pode ser justificada pela heterogeneidade das amostras em questão. O lodo B, por ser proveniente de uma zona de mistura do digestor, possui uma composição bastante heterogênea, além de ser mais fluido, quando comparado ao lodo A. Isso pode ser atestado pela diferença dos valores do desvio padrão, que para o lodo B foram mais elevados.

As concentrações de NPK e dos demais nutrientes dos lodos A e B estão entre as médias encontradas nos trabalhos realizados por Guedes et al. (2006), Silva et al. (2006), Agustini \& Onofre (2007),

Tabela 2 - Valores médios e desvios padrão de carbono total, nitrogênio total, lipídios e relação carbono/nitrogênio para os lodos A e B durante o processo de desidratação.

\begin{tabular}{|c|c|c|c|c|c|}
\hline Ponto de coleta & Tempo (dias) & Carbono orgânico total (\%) & Nitrogênio total (\%) & Relação carbono/nitrogênio & Lipídios (\%)* \\
\hline \multirow{3}{*}{$\begin{array}{l}\text { A } \\
(4,8 \mathrm{~m})\end{array}$} & 7 & $31,67 \pm 2,35 a$ & $3,35 \pm 0,39$ & $9,55 \pm 1,47 a$ & \\
\hline & 30 & $25,04 \pm 2,01 \mathrm{c}$ & $3,67 \pm 0,65$ & $7,02 \pm 1,65 b$ & \\
\hline & 60 & $21,89 \pm 1,26 d$ & $4,23 \pm 0,74$ & $5,26 \pm 0,70 b$ & \\
\hline \multirow{4}{*}{$\begin{array}{l}\text { B } \\
(3,1 \mathrm{~m})\end{array}$} & O & $35,76 \pm 3,97 a$ & $3,14 \pm 0,01$ & $11,39 \pm 1,27 a$ & 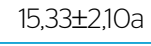 \\
\hline & 7 & $31,38 \pm 0,94 a$ & $3,39 \pm 0,82$ & $9,65 \pm 2,38 a$ & \\
\hline & 15 & $31,07 \pm 2,84 a$ & $3,03 \pm 0,64$ & $10,73 \pm 3,41 a$ & \\
\hline & 30 & $25,74 \pm 4,57 b$ & $3,23 \pm 0,71$ & $8,06 \pm 0,89 b$ & \\
\hline
\end{tabular}

* $\mathrm{p}<0,10$; médias ( $\mathrm{n}=3$ ) seguidas de mesma letra na coluna de um mesmo ponto de coleta não diferem entre si, pelo teste de Scott-Knott $(\alpha=0,05)$.

Tabela 3 - Valores médios e desvios padrão da concentração, em $\mathrm{g} \mathrm{kg}^{-1}$, de massa seca de macro e micronutrientes nos tratamentos A e B, aos 90 dias de secagem.

\begin{tabular}{l|c|c|c|c|c|c} 
& $\mathrm{K}$ & $\mathrm{P}$ & $\mathrm{Ca}$ & $\mathrm{Mg}$ & $\mathrm{Mn}$ & $\mathrm{Na}$ \\
\hline $\mathrm{A}(4,8 \mathrm{~m})$ & $2,90 \pm 0,80$ & $16,07 \pm 25,28$ & $34,80 \pm 5,50$ & $3,30 \pm 1,17$ & $0,11 \pm 0,031$ & $1,85 \pm 0,85$ \\
\hline $\mathrm{B}(3,1 \mathrm{~m})$ & $3,64 \pm 1,61$ & $40,34 \pm 36,67$ & $41,88 \pm 23,71$ & $3,90 \pm 1,84$ & $0,13 \pm 0,06$ & $1,63 \pm 0,61$ \\
\hline
\end{tabular}


Freier, Malavasi e Malavasi (2006) e Carbonell et al. (2009). De forma geral, as concentrações finais de carbono e dos nutrientes analisados conferem aos lodos em estudo um potencial agronômico, sendo que a necessidade desses nutrientes para as plantas varia entre as culturas.

$\mathrm{Na}$ Tabela 4 estão representados os teores de metais pesados dos dois tratamentos pesquisados, comparados com os limites máximos permitidos pela Resolução CONAMA 375/06 (BRASIL, 2006). Com exceção do $\mathrm{Zn}$, os outros metais não apresentaram diferença estatística entre os tratamentos A e B, pelo teste de SNK $(\alpha=0,05)$.

O metal de maior concentração, nos lodos A e B, foi o zinco. Segundo Smith (2009), essa característica é comum em amostras de lodo de esgoto. Os valores encontrados para $\mathrm{Ni}, \mathrm{Co}, \mathrm{Pb}, \mathrm{Cu}$ e $\mathrm{Zn}$ estão de acordo com os resultados de Goi, Tubaro e Dolcetti (2006), Guedes et al. (2006), Agustini \& Onofre (2007), Salihoglu, Pinarli e Salihoglu (2007) e Carbonell et al. (2009). Nas pesquisas realizadas por Tsutiya (1999), Freier, Malavasi e Malavasi (2006) e Dacera \& Babel (2008), as concentrações de $\mathrm{Pb}$ e $\mathrm{Zn}$ também foram semelhantes, entretanto, os valores de $\mathrm{Cu}$ e Ni diferiram por serem muito mais elevados.

Para ambos os tratamentos, verifica-se que todas as concentrações estão abaixo dos limites máximos permitidos pela Resolução CONAMA no 375/06. Os valores de cobalto, não referidos nessa resolução, estão de acordo com o valor máximo permitido pela resolução sueca, que admite até $60 \mathrm{mg} \cdot \mathrm{kg}^{-1}$ de massa seca desse elemento (ATEC, 2002). Nesse sentido, conclui-se que, em relação a esse parâmetro, os lodos pesquisados podem ser utilizados na agricultura.

\section{Avaliação microbiológica do lodo}

Para os CTO (Tabela 5) foi encontrada uma média inicial de 6,39 e 6,92 ciclos-log nos lodos A e B, respectivamente. Nos primeiros 15 dias, o lodo $B$ apresentou uma queda acentuada de 3,1 ciclos, entretanto, aos 60 dias de tratamento, sua concentração estava próxima ao valor inicial (6,50 ciclos), decaindo 2,4 ciclos no $90^{\circ}$ dia. O lodo A, aos 60 dias, estava com a menor concentração de CTO de todo o processo (3,7 ciclos), mas essa concentração voltou a aumentar, totalizando 4,62 ciclos aos 90 dias. Sendo assim, a redução de CTO de todo o período foi de 1,77 e 2,80 ciclos, para os lodos A e B, respectivamente.

$\mathrm{O}$ aumento de CTO no lodo $\mathrm{B}$ aos 60 dias pode ser creditado à contaminação externa da primeira descarga. $O$ fato de os leitos ficarem descobertos permitiu a entrada de animais como pássaros e gatos, que exploravam o local e por vezes defecavam dentro dos leitos. Dessa forma, durante a coleta, o material fecal recente desses animais pode ter contaminado a amostra de lodo, aumentando de forma

Tabela 4 - Concentrações médias e desvios padrão, em mg.kg-1, de MS de metais pesados nos tratamentos A e B, aos 90 dias de secagem, e valores da Resolução CONAMA n 375/06.

\begin{tabular}{l|c|c|c|c|c|c} 
& $\mathrm{Ni}$ & $\mathrm{Co}$ & $\mathrm{Pb}$ & $\mathrm{Cu}$ & $\mathrm{Zn}$ & $\mathrm{Cd}$ \\
$\mathrm{A}(4,8 \mathrm{~m})$ & $53,98 \pm 8,15$ & $10,44 \pm 3,06$ & $206,14 \pm 29,48$ & $34,64 \pm 8,41$ & $894,07 \pm 81,00$ & traços* \\
\hline $\mathrm{B}(3,1 \mathrm{~m})$ & $61,13 \pm 26,87$ & $12,28 \pm 4,23$ & $202,67 \pm 39,55$ & $44,48 \pm 19,97$ & $1084,61 \pm 607,27$ & traç,0s* \\
\hline $\begin{array}{l}\text { Resolução CONAMA } \\
\text { n' 375 (Brasil, 2006) }\end{array}$ & 420 & - & 300 & 1500 & 2800 & 39 \\
\hline
\end{tabular}

*Indicam valores abaixo do limite detectável pelo método utilizado (2 mg.kg').

Tabela 5 - Médias e desvios padrão das concentrações logarítmicas dos microrganismos e presença de Salmonella spp. em $10 \mathrm{~g}$ de sólidos totais, durante os 90 dias do processo de secagem.

\begin{tabular}{|c|c|c|c|c|}
\hline Ponto de descarga & Tempo (dias) & Coliformes totais & Coliformes termotolerantes & Salmonela \\
\hline \multirow{6}{*}{$\begin{array}{l}\text { A } \\
(4,8 \mathrm{~m})\end{array}$} & O & $6,39 \pm 0,17$ & $5,97 \pm 1,00$ & \multirow{12}{*}{ Presença } \\
\hline & 7 & $5,72 \pm 1,51$ & $5,08 \pm 2,05$ & \\
\hline & 15 & $4,80 \pm 0,95$ & $4,67 \pm 0,90$ & \\
\hline & 30 & $5,39 \pm 1,02$ & $4,80 \pm 1,49$ & \\
\hline & 60 & $3,70 \pm 0,30$ & $3,12 \pm 0,84$ & \\
\hline & 90 & $4,62 \pm 1,05$ & $3,66 \pm 0,96$ & \\
\hline \multirow{6}{*}{$\begin{array}{l}\text { B } \\
(3,1 \mathrm{~m})\end{array}$} & O & $6,92 \pm 0,21$ & $6,70 \pm 0,1) a$ & \\
\hline & 7 & $5,53 \pm 1,03$ & $4,95 \pm 0,45 b$ & \\
\hline & 15 & $3,80 \pm 1,72$ & $3,74 \pm 0,81 b$ & \\
\hline & 30 & $4,92 \pm 1,85$ & $3,95 \pm 1,70 b$ & \\
\hline & 60 & $6,50 \pm 2,21$ & $4,03 \pm 0,43 b$ & \\
\hline & 90 & $4,08 \pm 0,96$ & $3,50 \pm 1,24 b$ & \\
\hline
\end{tabular}

Médias (n=3) seguidas de mesma letra na coluna de um mesmo ponto de coleta não diferem entre si, pelo teste de Skott-Knott $(\alpha=0,05)$. 
considerável o número de CTO, o que, por consequência, interferiu na média das demais descargas para esse tempo.

De forma geral, para os CTE, a redução foi mais significativa $(2,31$ e 3,20 $\log _{10}$, para os lodos A e B, respectivamente). Ao final do processo de secagem, o lodo A apresentou uma concentração de 3,66 $\log _{10}$ e o lodo B, de $3,50 \log _{10}$.

Almeida et al. (2006) encontraram as concentrações de $1,3 \times 10^{7} \cdot \mathrm{g}^{-1}$ de matéria seca do NMP de CTO e CTE de $1,4 \times 10^{7} \cdot \mathrm{g}^{-1}$ de matéria seca em lodo anaeróbio submetido a 60 dias em leito. Concluíram que o processo anaeróbio, seguido por desaguamento em leitos de secagem, é insuficiente para reduzir os patógenos presentes no lodo de esgoto a níveis considerados seguros para uso agrícola.

Em relação à salmonela, observa-se que ela se manteve presente ao longo do tratamento. Resultados semelhantes foram encontrados por Poucher et al. (2005) e Wéry et al. (2008). Esses últimos, utilizando a técnica de reação em cadeia da polimerase (PCR), monitoraram a quantidade de diferentes bactérias patogênicas no lodo proveniente de uma ETE da França. Após a secagem, o lodo apresentou de 4 a 5 ciclos-log por unidade de salmonela. Para esses autores, o comportamento da salmonela está correlacionado à sua capacidade intrínseca de lidar com estresses bióticos e abióticos.

A salmonela tem sido isolada de uma grande variedade de espécies de animais. Nos países industrializados, as gastroenterites causadas por essa bactéria são as de maior interesse. Essas doenças são resultantes da ingestão de alimentos contaminados, como bife mal cozido, porco, frango, frutos do mar e ovos (HILBERT et al., 2011). Atualmente, a contaminação de frutas e vegetais crus pela salmonela tem aumentado de forma considerável, entretanto, o aumento do foco no consumo desse tipo de vegetal como fonte de alimento saudável alerta para a necessidade de certificar-se que o produto não está contaminado por essa bactéria, principalmente em frutas e hortaliças orgânicas (JACOBSEN \& BECH, 2012).

Segundo Winfield \& Groisman (2003), a salmonela é capaz de sobreviver a uma grande variedade de estresses (flutuações de temperatura e $\mathrm{pH}$, alta osmolaridade e pouco nutriente disponível, luz do sol) e ambientes (aquáticos e terrestres). Para esses autores, essas características adaptativas estão relacionadas a genes específicos presentes nesse gênero.

A análise estatística das amostras de lodo revelaram que não houve diferença significativa $(\alpha=0,05)$ entre os lodos A e B, pelo teste $t$ de Student, para os microrganismos em estudo, em cada um dos tempos analisados (Tabela 5). Dentro do mesmo tratamento, apenas as concentrações dos CTE variaram de acordo com o tempo de exposição em leito. Vale salientar que foram realizadas análises de regressão entre os parâmetros físico-químicos e os microrganismos, entretanto, nenhum dos parâmetros teve influência significativa na sobrevivência dessas bactérias.
A presença de altos índices de microrganismos até o final dos três meses de secagem do lodo indica necessidade de sua higienização antes do uso agrícola em culturas destinadas a receber lodo classe A (BRASIL, 2006). A depender das condições de estocagem do biossólido, de sua aplicação no solo e de fatores físico-químicos e biológicos do solo, muitos microrganismos, principalmente a salmonela, podem retomar seu crescimento (SIDHU \& TOZE, 2009). Qi, Dentel e Herson (2008), simulando condições de estocagem de lodo proveniente de digestão anaeróbia mesofílica e desaguamento por centrifugação (19,1\% de ST), encubaram as amostras a $25^{\circ} \mathrm{C}$ por 6 dias e observaram que houve um recrescimento de CTO de 5 para 8 ciclos-log por NMP.g-1 de massa seca.

Como é sabido, o contato direto e indireto com o solo contaminado pode causar infecções ao homem e aos animais. Frutas e vegetais frescos contaminados com salmonela são fontes primárias de infecção para o ser humano. Em geral, essa contaminação ocorre diretamente pela semente ou, ainda, pelo contato da bactéria com a parte comestível da planta devido aos respingos de água da irrigação ou de chuva, por exemplo (JACOBSEN \& BECH, 2012). É esse processo que contribui para fechar o ciclo do patógeno, que, uma vez eliminado nas fezes do animal hospedeiro, permanece no lodo utilizado na adubação, contaminando o alimento e, em seguida, retorna ao hospedeiro por meio da ingestão desse alimento contaminado.

Com relação à segurança microbiológica do uso dos lodos estudados para a agricultura, esses são classificados como classe $B$, de acordo com a Resolução CONAMA n 375/06 (BRASIL, 2006) (Tabela 3), pois, considerando as concentrações finais dos CTE, ambos apresentaram valores acima de $10^{3}$ NMP.g ${ }^{-1}$ de ST (lodo A: 3,66 $\log _{10}$ e lodo B: 3,50 $\log _{10}$ ), além da presença de Salmonella spp. em $10 \mathrm{~g}$ de ST. Dessa forma, considerando o parâmetro microbiológico, os lodos A e B podem ser utilizados apenas para culturas de grande porte e reflorestamento.

Na Tabela 6 estão representadas as concentrações de ovos viáveis de helmintos no início e no final do período de secagem.

A partir dos resultados encontrados, observou-se que as eficiências de remoção de ovos viáveis foram semelhantes entre os tratamentos: 97,37 e 99,69\%, para os lodos A e B, respectivamente.

A temperatura de $30^{\circ} \mathrm{C}$ e a elevada umidade (mais de $90 \%$ ) do lodo na fase inicial podem ter favorecido a maturação e eclosão dos ovos de helmintos, reduzindo sua concentração ao final do processo.

Tabela 6 - Médias e desvios padrão da concentração de ovos viáveis de helmintos. $\mathrm{g}^{-1}$ de sólidos totais nos tratamentos A e B.

\begin{tabular}{l|c|c}
\multirow{2}{*}{ Ponto de descarga } & Tempo (dias) & $\begin{array}{c}\text { Número de ovos viáveis de } \\
\text { helmintos. } \text { g }^{-1} \text { de sólidos totais }\end{array}$ \\
\cline { 2 - 3 } A & 0 & $107,90 \pm 175,96$ \\
\hline \multirow{2}{*}{ B } & 90 & $2,84 \pm 3,11$ \\
\cline { 2 - 3 } & 0 & $141,21 \pm 216,64$ \\
\hline
\end{tabular}


Além disso, a redução da umidade, já no final do tratamento, pode ter inviabilizado muitos ovos viáveis por dessecação.

Em contrapartida a esse trabalho, Koné et al. (2007) analisaram a presença de Ascaris spp. e Trichuris spp. em lodo de tanque séptico e banheiros públicos submetidos a leito e encontraram 42 ovos viáveis g.ST ${ }^{-1}$. Após aumento de ST>20\%, o valor caiu para 15 ovos. Esses autores concluíram que a secagem do lodo em leitos não é um processo eficiente para inativar todos os ovos de helmintos.

Dado o exposto, o lodo anaeróbio da ETE Contorno encontra-se de acordo com os parâmetros parasitológicos estabelecidos pela Resolução CONAMA n 375/06 para classificação como classe B, já que apresenta um número menor do que 10 ovos viáveis. ${ }^{-1}$ de matéria seca.

\section{CONCLUSÃO}

De acordo com a análise estatística dos dados obtidos, não há diferença físico-química, microbiológica e parasitológica entre os lodos A (4,8 m) e B (3,1 m) durante o período de secagem em leito. Considerando apenas o teor de ST, o lodo B pode ser removido do leito com 30 dias de secagem, e o lodo A, com 60 dias. As concentrações finais dos nutrientes e metais pesados bem como a relação $\mathrm{C} / \mathrm{N}$ conferem aos lodos em estudo um potencial agronômico.

Dentre os microrganismos analisados, os CTE apresentaram maior redução decimal logarítmica, enquanto a salmonela persistiu até o final do processo de secagem.

A partir dos dados microbiológicos obtidos, observa-se que o processo de desaguamento de lodo em leitos de secagem é insuficiente para reduzir os patógenos presentes a níveis considerados seguros para uso agrícola.

Em relação aos ovos viáveis de helmintos, o processo de secagem foi eficaz, pois promoveu a remoção significativa desses ovos, reduzindo os valores a um número menor do que 10. Os biossólidos gerados em ambos os tratamentos são classificados como tipo B, de acordo com a Resolução CONAMA nº 375/06.

\section{REFERÊNCIAS}

AGUSTINI, D. \& ONOFRE, S.B. (2007) Caracterização físico-química e microbiológica do lodo de esgoto produzido pela estação de tratamento de esgoto (ETE) de Pato Branco - PR. Revista de Biologia e Saúde da UNISEP, v. 1, n. 1, p. 82-95.

ALMEIDA, G.C.; FANHANI, J.C.; D'OLIVEIRA, P.S.; DIAS FILHO, B.P. (2006) Eficiência dos processos químico e térmico na higienização de lodo de esgoto. Iniciação Científica CESUMAR, v. 8, n. 1, p. 95-99.

ALVES, M.M.; VIEIRA, J.A.M; PEREIRA, R.M.A.; PEREIRA, M.A.; MOTA, M. (2001) Effect of lipids and oleic acid on biomass development in anaerobic fixed-bed reactors. Part I: Biofilm growth and activity. Water Research, v. 35, n. 1, p. 255-263.

AMERICAN PUBLIC HEALTH ASSOCIATION; AMERICAN WATER WORKS ASSOCIATION; WATER ENVIRONMENT FEDERATION APHA/AWWA/WEF. (1998) Standard Methods for the Examination of Water and Wastewater. 2Oth ed. Washington: APHA/AWWA/WEF.

ASSOCIAÇÃO BRASILEIRA DE NORMAS TÉCNICAS - ABNT. (1989) NBR 10664: águas - determinação de resíduos (sólidos) - método gravimétrico. Rio de Janeiro: ABNT.

ASSOCIAÇÃO BRASILEIRA DE NORMAS TÉCNICAS - ABNT. (1992) NBR 12209: Projeto de estação de tratamento de esgoto sanitário. Rio de Janeiro: ABNT.

BERTOLDI, M.; VALLINI, G.; PERA, A. (1983) The biology of composting: a review. Waste Management \& Research, v. 1, n. 2, p. 157-176.

BRASIL. (2006) Resolução CONAMA n० 375, de 29 de agosto de 2006. Define critérios e procedimentos, para o uso agrícola de lodos em estações de tratamento de esgoto sanitário e seus produtos derivados, e dá outras providências. Brasília: Diário Oficial da República Federativa do Brasil.

CARBONELL, G.; PRO, J.; GÓMES, N.; BABÍN, M.M.; FERNÁNDEZ, C.; ALONSO, E.; TARAZONA, J.V. (2009) Sewage sludge applied to agricultural soil: ecotoxicological effects on representative soil organisms. Ecotoxicology and Environmental Safety, v. 72 n. 4, p. 1309-1319.

CECCHI, H.M. (1999) Fundamentos teóricos e práticos em análise de alimentos. Campinas: Editora da UNICAMP.

DACERA, D.D.M. \& BABEL, S. (2008) Removal of heavy metals from contaminated sewage sludge using Aspergillus niger fermented raw liquid from pineapple wastes. Bioresource Technology, v. 99, n. 6, p. 1682-1689.

DIPARTIMENTO FEDERALE DELL'AMBIENTE, DEI TRASPORTI, DELL'ENERGIA E DELLE COMUNICAZIONI - ATEC. (2OO2). Rapporto Esplicativo: concernente le modifiche delle prescrizioni relative ai fanghi di depurazione dell' ordinanza sulle sostanze e di altre ordinanze federali. Berna: ATEC.

FREIER, M.; MALAVASI, U.C.; MALAVASI, M.M. (2006) Efeitos da aplicação de biossólido no crescimento inicial de Eucalyptus citriodora Hook. Revista de Ciências Agroveterinárias, v. 5, n. 2, p. 102-107.

FYTILI, D. \& ZABANIOTOU, A. (2008) Utilization of sewage sludge in EU application of old and new methods; a review. Renewable and Sustainable Energy Reviews, v. 12, n. 1, p. 116-140. 
GOI, D.; TUBARO, F.; DOLCETTI, G. (2006) Analysis of metals and EOX in sludge from municipal wastewater treatment plants: a case study. Waste Management, v. 26, n. 2, p. 167-175.

GUEDES, M.C.; ANDRADE, C.A.; POGGIANI, F.; MATTIAZZO, M.E. (2006) Propriedades químicas do solo e nutrição do eucalipto em função da aplicação de lodo de esgoto. Revista Brasileira de Ciência do Solo, v. 30, n. 2, p. 267-280.

HILBERT, F.; SMULDERS, F.J.M.; CHOPRA-DEWASTHALY, R.C.; PAULSEN, P. (2011) Salmonella in the wildlife-human interface. Food Research International, v. 45, n. 2, p. 603-608.

JACOBSEN, C.S. \& BECH, T.B. (2012) Soil survival of Salmonella and transfer to freshwater and fresh produce. Food Research International, v. 45, n. 2, p. 557-566.

KONÉ, D; COFIE, O.; ZURBRÜGG, C.; GALLIZZI, K.; MOSER, D.; DRESCHER, S.; STRAUSS, M. (2007) Helminth eggs inactivation efficiency by faecal sludge dewatering and co-composting in tropical climates. Water Research, v. 41, n. 19, p. 4397-4402.

POUCHER, A.M.; MORAND, P.; PICARD-BONNAUD, F.; BILLAUDEL, S.; MONPOEHO, S.; FEDERIGHI, M.; FERRÉ, V.; MOGUEDET, G. (2005) Decrease of enteric micro-organisms from rural sewage sludge during their composting in straw mixture. Journal of Applied Microbiology, v. 99, n. 3, p. 528-539.

PROGRAMA DE PESQUISA EM SANEAMENTO BÁSICO - PROSAB. (1999). Manual prático para a compostagem de biossólidos. Rio de Janeiro: Associação Brasileira de Engenharia Sanitária e Ambiental.

QI, Y.; DENTEL, S.K.; HERSON, D.S. (2008) Effect of total solids on fecal coliform regrowth in anaerobically digested biosolids. Water Research, v. 42, n. 14, p. 3817-3825.

SALIHOGLU, N.K:; PINARLI, V; SALIHOGLU, G. (2007) Solar drying in sludge management in Turkey. Renewable Energy, v. 32, n. 10, p. 1661-1675.

SIDHU, J.P. \& TOZE, S.G. (2009) Human pathogens and their indicators in biosolids: a literature review. Environment Internacional, v. 35, n. 1, p. 187-201.
SILVA, C.A.; RANGEL, O.J.; DYNIA, J.F.; BETTIOL, W.; MANZATTO, C.V. (2006) Disponibilidade de metais pesados para milho cultivado em Latossolo sucessivamente tratado com lodos de esgoto. Revista Brasileira de Ciência do Solo, v. 30, n. 2, p. 353-364.

SILVA, M.M.P.; SILVA, A.G.; SOUZA, J.T.; CEBALLOS, B.S.O.; LEITE, V.D. (2007) Avaliação da remoção de ovos de helmintos em codisposição de lodo anaeróbio e resíduos sólidos orgânicos. In: XXIV Congresso Brasileiro de Engenharia Sanitária e Ambiental, Anais Eletrônico... Belo Horizonte: ABES.

SMITH, S.R. (2009) A critical review of the bioavailability and impacts of heavy metals in municipal solid waste composts compared to sewage sludge. Environment International, v. 35, n. 1, p 142-156.

TSUTIYA, M.T. (1999) Metais pesados: o principal fator limitante para o uso agrícola de biossólidos das estações de tratamento de esgotos. In: XX Congresso Brasileiro de Engenharia Sanitária e Ambiental, 20, Anais... Rio de Janeiro: ABES.

UNITED STATES ENVIRONMENTAL PROTECTION AGENCY USEPA. (2003) EPA 625/R-92/013: Under 40 CFR Parte 503. Environmental Regulations and Technology. Control of Pathogens and Vector Attraction in Sewage Sludge (Including Domestic Septage). Washington: USEPA.

WAGNER, A.O.; MALIN, C.; GSTRAUNTHALER, G.; ILLMER, P. (2009) Survival of selected pathogens in diluted sludge of a thermophilic waste treatment plant and in $\mathrm{NaCl}$-solution under aerobic and anaerobic conditions. Waste Management, v. 29 , n. 1, p. 425-429.

WÉRY, N.; LHOUTELLIER, C.; DUCRAY, F.; DELGENES, J.P.; GODON, J.J. (2008) Behaviour of pathogenic and indicator bacteria during urban wastewater treatment and sludge composting, as revealed by quantitative PCR. Water Research, v. 42 , n. 1-2, p. 53-62.

WINFIELD, M.D. \& GROISMAN, E.A. (2003) Role of nonhost environments in the lifestyles of Salmonella and Escherichia coli. Applied and Environmental Microbiology, v. 69, n. 7. p. 3687-3694. 